\title{
Ensino de Introdução à Programação na Modalidade Semipresencial com o Apoio do Google Classroom
}

\author{
Hígor R. Monteiro Santos, Franciely Alves de Souza, Bruno Barboza dos Santos, \\ Irandir Onofre de Amorim, Maria R. Barbosa da Silva e Adauto T. Almeida Filho \\ Universidade de Pernambuco, Campus Garanhuns (UPE), CEP 55.294-902, PE - Brazil \\ higor.monteiro@upe.br, ffrancielyalves835, brunobarboza3103, \\ irandironofre5, renaybarbosa\}@gmail.com, adauto.filho@upe.br
}

\begin{abstract}
This paper reports the experience undergone by students of the course of Degree in Computation of the University of Pernambuco Campus Garanhuns in the accomplishment of the discipline Supervised Stage IV. In this sense, the practice developed addresses the teaching of Computation in the blended mode with support from Google Classroom for Elementary School students. The results present opportunities that the teachers have when dealing with the teaching of Computation in the semipresencial modality in basic education. In addition, it was evidenced that the students of the elementary school managed to obtain an excellent performance in the face and distance classes in an autonomous, playful and pleasurable way.

Resumo. Este artigo relata a experiência vivenciada por discentes do curso de Licenciatura em Computação da Universidade de Pernambuco - Campus Garanhuns na realização da disciplina Estágio Supervisionado IV. Nesse sentido, a prática desenvolvida aborda o ensino de Computação na modalidade semipresencial com apoio do Google Classroom para alunos do Ensino Fundamental. Os resultados obtidos apresentam oportunidades que os licenciandos têm, enquanto docentes, ao lidar com o ensino de Computação na modalidade semipresencial na educação básica. Além disso, evidenciou-se que os alunos do ensino fundamental conseguiram obter um ótimo desempenho nas aulas presenciais e à distância de forma autônoma, lúdica e prazerosa.
\end{abstract}

\section{Introdução}

São notáveis a evolução e os impactos positivos que a tecnologia da informação tende a contribuir para as pessoas na resolução de problemas atuais e futuros. Podemos observar que o meio em que vivemos está permeado pelo uso de técnicas e recursos tecnológicos, fazendo do computador uma ferramenta que vem auxiliar questões do cotidiano trazidas até a sala de aula no processo de ensino e aprendizagem. Nesse sentido, Moreira et al. (2007) ressalta que a utilização da tecnologia na educação tem afetado positivamente o modo estrutural do ambiente escolar e do próprio trabalho docente.

O ensino de Computação está contido nessa evolução tecnológica e tem contribuído para desenvolver em crianças e jovens habilidades para lidar com resoluções de problemas, tais como, raciocínio lógico, criatividade e trabalho em equipe [Ferreira et al.2015]. Apesar dos esforços da SBC e das demais comunidades acadêmicas, ainda não existe uma sistematização e uma formalização no currículo escolar para o ensino de Computação, enquanto ciência, na educação básica. No entanto, é possível evidenciar diversas iniciativas de sucesso promovidas por estudantes e professores universitários nesse sentido, as quais são colocados em prática nas escolas das mais diversas formas 
(Oliveira et al. 2014; Neto et al. 2013; Scaico et al. 2013). O sucesso destes trabalhos, deu-se por utilizar ferramentas de criação de jogos, a ideia era ensinar lógica de programação criando jogos com os alunos com temas referentes a outras disciplinas.

Nesse mesmo contexto educacional, a utilização de tecnologias na educação permite cada vez mais a expansão da modalidade de ensino à distância. Capacitar-se independente de distância, estudar após as aulas presenciais e a possibilidade do aluno fazer seus horários de estudos são alguns dos fatores que têm contribuído para a grande adesão da educação a distância (Belloni 1999). Outra modalidade que tem obtido bastante espaço por conciliar as boas práticas da educação presencial e a Educação à Distância (EAD) é a educação semipresencial. Para Bertagnolli et al. (2008), o ensino semipresencial pode ter aulas a distância com até $20 \%$ da carga horária total do curso. Esta é considerada uma ótima alternativa atualmente porque além de manter laços afetivos entre professor-aluno e aluno-aluno, também permite um acompanhamento formal das atividades a distância ao longo do curso (Voigt 2007).

Apesar do crescimento da EAD e de cursos semipresenciais no Brasil, a aplicação dessa modalidade para alunos da educação básica, principalmente no ensino fundamental, precisa ser mais explorada. O Decreto 9057/17' apresenta uma nova regulamentação para a EAD, permitindo-a inclusive na educação básica. Porém, na versão atual desse decreto, a EAD pode ser aplicada formalmente apenas para alunos do ensino médio com situações emergenciais e para complementação de aprendizagem.

Diante disso, pode-se perceber que tanto o ensino de Computação quanto a educação à distância com foco na educação básica são temas emergentes e que não há ainda uma formalização nas instituições de ensino no Brasil. Diante disso, enxerga-se como oportunidade a realização de formações (cursos, oficinas, palestras) independentes para cada vez mais gerar evidências de sucesso e promover a sistematização desses temas na educação básica.

Nesse contexto, a experiência relatada neste artigo apresenta os resultados obtidos de um curso na área de Computação (Introdução a Programação) na modalidade semipresencial com alunos do Ensino Fundamental II. O desafio de realizar esse curso foi proposto aos estudantes matriculados na disciplina Estágio Supervisionado do curso de Licenciatura em Computação da Universidade de Pernambuco, onde o objetivo era elaborar todo um planejamento e realização de um curso semipresencial ou totalmente a distância para alunos da educação básica.

\section{Revisão da literatura}

Nesta seção serão contextualizados estudos referentes ao ensino semipresencial, e suas contribuições para a educação, como também evidências que mostram o quanto os conceitos e práticas relacionadas a programação contribuem para o desenvolvimento do raciocínio lógico.

\subsection{Ensino Semipresencial}

Todas as áreas do conhecimento percebem o grande impacto das mudanças tecnológicas, onde a cada dia se exige diferentes habilidades para que a sociedade possa se habituar com tais evoluções. Mudanças essas que podem contribuir para organização de atividades e administração do tempo. A partir do desenvolvimento, da expansão e da apropriação das tecnologias digitais pela sociedade em geral, novas práticas sociais, políticas, 
econômicas, culturais emergem, dando origem ao ciberespaço e à cibercultura (Lévy 2008; Silva 2003; Ramal 2002).

Com a expansão das tecnologias presentes no processo de ensino e aprendizagem, pode-se destacar o avanço da modalidade de ensino semipresencial que conta com a vantagem da turma estar conectada em ambos e com seus educadores a qualquer horário, podendo utilizar ambientes virtuais como fóruns, sites e blogs, que podem ser usados como estratégias para potencializar a aprendizagem, pois assim o aluno tem a autonomia de participar das atividades e compartilhar materiais relacionados ao assunto estudado. Alguns autores como Moran (2005) e Levy (2008) defendem a internet como um espaço participativo e que estimula o pleno desenvolvimento também das competências e habilidades na formação do aluno.

Através do ensino semipresencial além das aulas presenciais, ocorre o acompanhamento virtual, onde os alunos podem aprender novos conteúdos, discutir sobre temas específicos e fazer questionamentos a fim de resolver eventuais dúvidas. Esse avanço da tecnologia está desencadeando novas formas de comunicação e interação no ambiente escolar (Ponte et al. 2003). Conforme suas características, o sucesso do ensino semipresencial depende também da responsabilidade dos estudantes para cumprir com as atividades não presenciais. Dessa forma, é necessário que o aluno tenha autonomia para planejar seus próprios horários dentro dos prazos estipulados. Além disso, com o auxílio de ambientes virtuais de aprendizagens (AVA), um ponto importante tratado no ensino semipresencial é a interação e aprendizagem em conjunto, onde os estudantes podem compartilhar informações que possam contribuir para o aprendizado de ambos, podendo efetuar perguntas diretamente ao professor, para os esclarecimentos de dúvidas ou auxílios em atividades.

\subsection{Ensino de Programação com Ferramentas Lúdicas}

O uso de tecnologias e artefatos lúdicos na educação básica, independente da área, está sendo cada vez mais crucial para o aprendizado dos alunos, uma vez que se tratam de recursos que fazem parte do dia a dia no qual estão inseridos. Entende-se que o computador provocou uma grande revolução na educação devido a sua capacidade de ensinar e que as possibilidades de implantação de novas técnicas de ensino são ilimitadas (Menezes e Gitahy 2010).

É nítido que quando a turma se sente engajada com os conhecimentos propostos, a aula segue um trajeto lúdico e atrativo. Esses aspectos são referentes ao quanto a tecnologia é propícia para promover um aprendizado enriquecedor e inovador que desperta o interesse dos alunos. Para Bettega (2010), a tecnologia deve servir para enriquecer o ambiente educacional de forma a propiciar a construção de conhecimentos por meio de uma atuação ativa, crítica e criativa por parte de alunos e professores. $\mathrm{O}$ ensino de computação, é importante para que desperte o interesse e curiosidade de conhecer e estudar, como os recursos tecnológicos funcionam e são desenvolvidos, assim construindo um conhecimento que vai além de apenas utilizar os recursos tecnológicos de maneira externa.

A educação deve se espelhar em métodos inovadores de ensino que possuem o objetivo de aguçar o desenvolvimento do raciocínio lógico e a resolução de problemas. Características essas que são intrínsecas no ensino e aprendizagem de programação de computadores (Scaico et al. 2013). Neste contexto, o ensino de programação para crianças poderia desenvolver o pensamento computacional e passos lógicos para a resolução automatizada de problemas (Kafai e Burke 2013). 


\subsection{Trabalhos Relacionados}

Esta seção destaca trabalhos relacionados ao ensino de Computação na modalidade semipresencial e presencial na educação básica, onde são apresentadas suas abordagens e contribuições dando ênfase no quanto a educação pode proporcionar a abordagem de conhecimentos por meios inovadores.

O trabalho de Ferreira et al (2015) se assemelha bastante com este trabalho. Eles apresentam uma experiência sobre a execução de um minicurso sobre introdução a programação para alunos do ensino médio na modalidade semipresencial. Utilizaram o Edmodo $^{2}$ como o ambiente virtual de aprendizagem AVA e evidenciaram que é possível ter bons resultados para esse público-alvo. Píccolo et al (2010) demonstra um tipo de adaptação do ensino semipresencial. Eles descrevem sobre um ambiente interativo chamado de TutorICC que está sendo desenvolvido e testado para o ensino superior. $\mathrm{O}$ TutorICC tem como função ensinar o aluno à distância o conteúdo de programação na linguagem PASCAL.

Júnior et al (2005) apesar de não trabalhar com ensino semipresencial ou ensino a distância esse artigo refere-se ao ensino de programação e algoritmos para alunos do ensino médio. A experiência ocorreu em forma de oficinas com duração de cerca 36 horas em uma escola do ensino médio. Schoeffel et al (2015) relata a experiência de um curso presencial de computação para o ensino fundamental com turmas do $7^{\circ}, 8^{\circ}$ e 9 ano. $\mathrm{O}$ curso não foca exclusivamente no ensino de programação. Ele divide o curso em duas partes, primeiro trabalha os conceitos através de ferramentas como jogos e brincadeiras. Na segunda parte, são trabalhadas atividades lúdicas e práticas de programação.

Oliveira et al (2014) descrevem um relato de experiência de um curso presencial de lógica de programação para alunos do $9^{\circ}$ ano. A principal contribuição é fazer com que os próprios alunos criem seus jogos, onde cada jogo tem uma história desenvolvida por eles e implementada no Scratch.

Ressalta-se que este trabalho se assemelha com trabalhos anteriores no que se refere a ensino de Computação e na modalidade semipresencial com o seguinte diferencial de trabalhar esses dois temas com alunos do ensino fundamental e utilizar um outro ambiente virtual de aprendizagem.

\section{Procedimentos metodológicos}

Diante do planejamento da disciplina de Estágio Supervisionado IV do curso de Licenciatura em Computação, a equipe composta pelos autores deste artigo determinou que o público-alvo para o minicurso seriam alunos do $7^{\circ}$ ano do Ensino Fundamental. As atividades ocorreram no laboratório de informática da Universidade de Pernambuco Campus Garanhuns e contou com a participação de 14 alunos da Escola de Aplicação Professora Ivonita Alves Guerra. Ressalta-se que as inscrições dos alunos participantes foram realizadas após divulgação presencial nas turmas da escola supracitada.

O plano de ensino do curso intitulado "Introdução a Programação" buscou atender os objetivos de trabalhar com a modalidade de ensino semipresencial e o planejamento e organização do curso caracterizou-se em três etapas: Divulgação do Minicurso, Seleção de Ferramentas e Definição das Aulas.

Divulgação: o objetivo foi despertar o interesse dos potenciais alunos pelo curso ofertado. Durante a divulgação presencial, foram realizadas apresentações em sala de 
aula, assim como foram deixados panfletos e cartazes. As matrículas foram efetuadas através de um formulário online, criado no Google Drive.

Seleção das ferramentas: foi realizada uma pesquisa com o objetivo de identificar ferramentas voltadas para o ensino de programação que abordam os seguintes requisitos: ter características lúdicas e possibilitar a abordagem dos conceitos com baixo nível de complexidade. As ferramentas selecionadas são: Light-Bot- um jogo online utilizado com o intuito de aplicar os conceitos de algoritmo e estrutura sequencial, onde o aluno implementa um passo a passo lógico para que o personagem chegue no seu objetivo. $\mathrm{ii}$. RoboMind - um ambiente de programação que permite o usuário se familiarizar com os conceitos básicos de Ciência da Computação programando seu próprio robô por meio de expressões lógicas; iii. Scratch - software prático e fácil que trabalha estruturas usadas na programação, como o uso de variáveis, constantes e operadores lógicos; iv. The Foos jogo que abrange os conceitos de programação, tais como recursão e loop. The Foos foi utilizado para os alunos entenderem como funciona uma função recursiva em uma linguagem de programação; $v$. VisualG - um ambiente de desenvolvimento que utiliza a linguagem de programação portugol, foi usado para revisão dos conceitos anteriormente trabalhados com base em pseudocódigo.

Definição das aulas (presenciais e à distância): por se caracterizar como um curso semipresencial, o planejamento foi categorizado em aulas presenciais e à distância. Para as aulas presenciais, foram definidos os conteúdos teóricos a serem trabalhados em cada aula e aplicação das ferramentas selecionadas a fim de promover um ensino lúdico e atraente para o perfil do público e as dinâmicas inspiradas na metodologia Computação Desplugada. Esta técnica consiste em ensinar os fundamentos da computação, através de atividades, sem o uso do computador Bell et al. (2011). O acompanhamento das atividades à distância foi realizado por meio do ambiente virtual de aprendizagem Google Classroom, o mesmo escolhido por causa da sua usabilidade fácil e praticidade. No AVA, os alunos tinham duas atividades por semana (um fórum de discussão e uma tarefa com entrega) para pesquisar e discutir sobre temas referentes ao conteúdo do curso.

De acordo Bairral (2007), o fórum de discussão é uma ferramenta comunicativa que todos podem acessar, ver o que está sendo discutido e participar da discussão com um tempo próprio para reflexão e resposta. Por sua vez, o WebQuest (WQ), de acordo com Dodge (2006), é um processo de ensino baseado na internet que possibilita uma investigação de informações e uma entrega documentada de forma organizada.

Como as aulas presenciais ocorreram apenas uma vez por semana, os alunos possuíam seis dias após a aula para organizar seus horários para estudar e realizar as atividades propostas à distância. Dessa forma, foi estimulada a autonomia para o próprio aluno escolher o melhor horário disponível para se dedicar aos estudos. Os tutores que mediaram o curso disponibilizaram slides, vídeos e sites de apoio de forma a incentivar os alunos a buscarem diferentes meios para construir o conhecimento.

Durante as aulas, eram abordados temas atrativos, como robótica educacional, roubo de identidade digital, os quais aguçaram a participação da turma. É válido destacar que o WhatsApp também foi utilizado como um espaço de comunicação frequente, sua escolha foi devido a falta de hábito dos alunos em utiliza o e-mail como meio de comunicação, o mesmo possibilita a discussão rápida dos conteúdos, informações sobre entrega de atividades, além de ter sido um meio para sugestões e críticas vindas dos alunos para possíveis melhorias do minicurso. No final do minicurso, um questionário para se obter a opinião dos alunos sobre o curso, foi aplicado, este questionário é apresentado na Seção 4.1 . 


\section{Relato da Experiência}

Nesta seção é apresentado o relato de experiência em relação ao curso semipresencial de Introdução à Programação para alunos do 7 ano do Ensino Fundamental. O desenvolvimento do curso foi planejado com sete aulas presenciais, com participação de 14 alunos, onde cada aula foi ministrada com a duração de 90 minutos. Para a realização das atividades e aprendizados à distância, os alunos precisavam se dedicar 3 horas por semana no intervalo de cada aula presencial. Nesse sentido, a carga horária total do curso foi de 28 horas.

\subsection{Aulas Presenciais}

Nas aulas presenciais, após a apresentação do conteúdo expositivo, utilizavam-se atividades dinâmicas relacionadas aos conceitos trabalhados com a intenção de tornar a aula mais atrativa. A Tabela 1 apresenta os conteúdos abordados em cada aula presencial e as dinâmicas realizadas.

\begin{tabular}{|c|c|}
\hline $1^{\text {a }}$ Aula & $\begin{array}{l}\text { 1. Apresentação do AVA Google Classroom e a metodologia do curso; } \\
\text { 2. Conceitos iniciais de algoritmo e softwares; } \\
\text { 3. } \\
\text { 4inâmica com algoritmos comuns do dia-a-dia; } \\
\text { 5. Apresentação da lógica de programação utilizando a ferramenta light-bot 2.0; }\end{array}$ \\
\hline $2^{\mathrm{a}}$ Aula & $\begin{array}{l}\text { 1. Revisão do conteúdo da Aula 1; } \\
\text { 2. } \quad \text { Conceitos de recursividade; } \\
\text { 3. Introduzir o funcionamento de uma função; } \\
\text { 4. Apresentar a ferramenta The Foos; } \\
\text { 5. } \quad \text { Apresentação das atividades EAD. }\end{array}$ \\
\hline $3^{\text {a }}$ Aula & 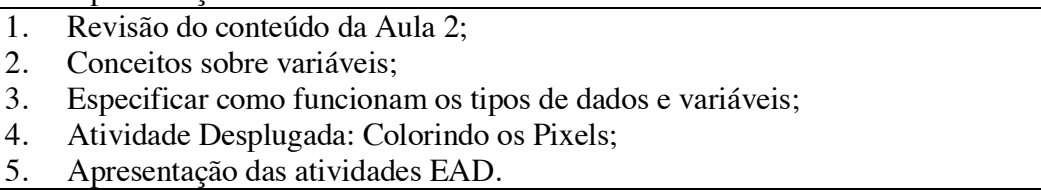 \\
\hline $4^{\mathrm{a}}$ Aula & 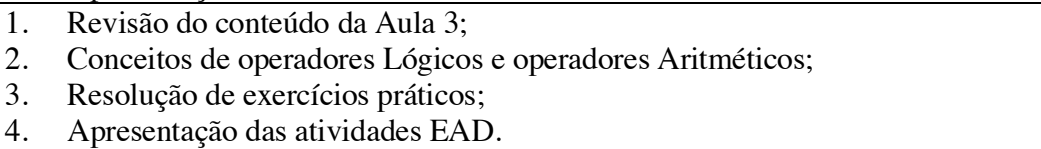 \\
\hline $5^{\text {a }}$ Aula & $\begin{array}{l}\text { 1. } \quad \text { Revisão do conteúdo da Aula 4; } \\
\text { 2. } \quad \text { Apresentação da ferramenta Scratch; } \\
\text { 3. } \quad \text { Resolução de exercícios práticos; } \\
\text { 4. } \quad \text { Apresentação das atividades EAD. }\end{array}$ \\
\hline $6^{a}$ Aula & 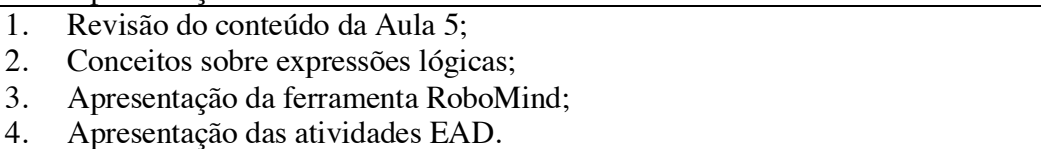 \\
\hline $7^{\text {a }}$ Aula & $\begin{array}{l}\text { 1. } \quad \text { Revisão do conteúdo da Aula 6; } \\
\text { 2. } \quad \text { Conceitos sobre estruturas de Seleção e estruturas de Repetição; } \\
\text { 3. }\end{array}$ \\
\hline
\end{tabular}

\section{Tabela 1. Conteúdo das aulas presenciais}

Como é possível observar, todas as aulas seguiram uma estrutura semelhante de apresentar novos conceitos e depois realizar práticas, seja em softwares ou por meio da computação desplugada. Cabe ressaltar que sempre ao final da aula eram apresentadas aos alunos as atividades que eles teriam que fazer ao longo da semana no Google Classroom. Por sua vez, a partir da segunda aula presencial, era feita uma revisão dos conteúdos abordados na aula anterior e reservava-se um momento para tirar dúvidas das atividades EAD que os alunos tinham que resolver ao longo da semana.

Sobre as aulas realizadas presencialmente, podemos perceber na Figura 1 uma interação dos alunos com a ferramenta RoboMind, a qual despertou o interesse por se tratar de um ambiente dinâmico e atrativo. Nesse caso, foram abordados conceitos sobre estrutura de repetição vistos na aula expositiva. 


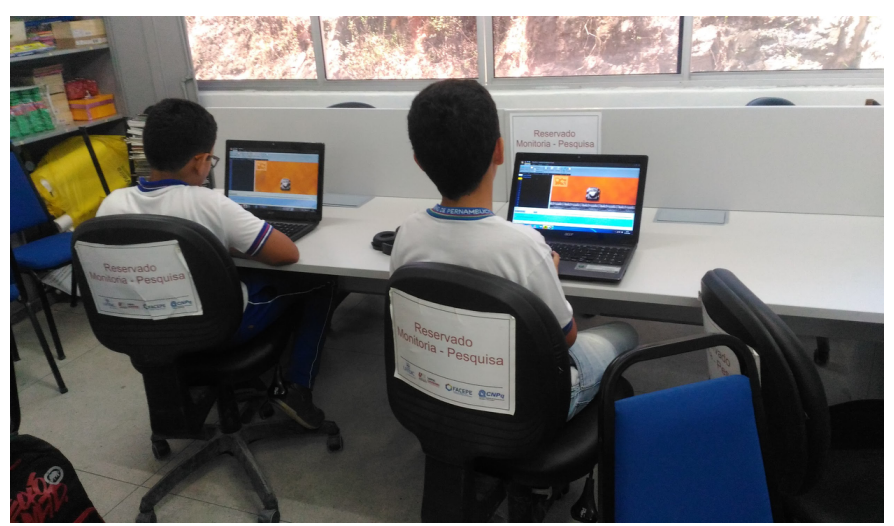

Figura 1. Alunos utilizando o software Robomind.

Com a intenção de analisar se esses procedimentos metodológicos tiveram um impacto positivo, foi construído e aplicado um questionário para que os alunos pudessem avaliar sua experiência. A Tabela 2 demonstra as respostas dos 14 alunos participantes.

\begin{tabular}{|l|l|}
\hline \multicolumn{1}{|c|}{ Questões } & \multicolumn{1}{|c|}{ Respostas } \\
\hline $\begin{array}{l}\text { 1- O curso contribuiu para aprimorar conhecimentos prévios } \\
\text { que você já possuía? }\end{array}$ & Concordo ( 13 ) Indeciso ( 01 ) Discordo ( 0 ) \\
\hline 2- Participaria de outro curso com essa temática? & Concordo ( 14 ) Indeciso ( 0 ) Discordo ( 0 ) \\
\hline $\begin{array}{l}\text { 3- Acredita que com o uso de softwares, as aulas passam a } \\
\text { ser mais dinâmicas e a compreensão dos conteúdos se torna } \\
\text { mais fácil? }\end{array}$ & Concordo ( 12) Indeciso (02) Discordo ( 0 ) \\
\hline $\begin{array}{l}\text { 4- Acredita que as tecnologias deveriam ser algo presente } \\
\text { frequentemente na escola? }\end{array}$ & Concordo ( 13 ) Indeciso (01 ) Discordo ( 0 ) \\
\hline
\end{tabular}

Tabela 2. Dados de questionário.

Conforme os resultados obtidos na Tabela 2, pode-se observar que os alunos tiveram uma experiência positiva em relação aos conteúdos e o formato das aulas. Evidencia-se que o curso contribuiu para aprimorar conhecimentos prévios e que eles aceitariam participar de outro curso com essa mesma temática. Apenas dois alunos ficaram indecisos e 12 concordaram com a afirmativa de que as aulas passam a ser mais dinâmicas e a compreensão dos conteúdos se torna mais fácil com o uso de softwares. De forma semelhante, a maioria concordou que as tecnologias deveriam ser algo presente frequentemente na escola.

Além das questões apresentadas na Tabela 2 , também foi pedida a opinião de cada aluno referente ao planejamento e execução de curso a fim de investigar em quais pontos seria necessário melhorar para se ofertar um curso com essa modalidade. Na Figura 2 estão descritas algumas das respostas obtidas.

Sim, achei o curso bem produtivo e gostei principalmente pelo fato de que a maioria das aulas foram bem
dinâmicas, nós aplicávamos o que tínhamos aprendido em jogos.
Sim, além de uma aula que não era muito longa, sempre tinham atividades referentes aos assuntos muito
interessantes.
Sim, gostei muito da dinâmica das aulas práticas.
eu gostei bastante, as aulas foram de grande conhecimento pra mim que tinha pouco conhecimento sobre.
Sim, gostei da interação com os alunos e dos materiais usados em aula.
Sim, foi de maneira bem simples e fácil de se entender.
Sim, de maneira bem prática e simples de se entender.

Figura 2. Respostas do questionamento feito em sala.

Após a aplicação do questionário, foi possível corroborar os fatores positivos que os mediadores das aulas observavam através da interação e participação dos alunos em sala de aula e no próprio ambiente virtual nas atividades à distância. 


\subsection{Aulas à Distância}

As aulas e momentos em que os alunos realizaram atividades à distância ocorreram por meio da plataforma Google Classroom. Esse ambiente permite que todo o material e conteúdo possam ser compartilhados e agendados com a data, horário de liberação das atividades e fechamento de forma automática. Dessa forma, foram disponibilizados na plataforma os slides das aulas presenciais, materiais de apoio e links úteis que complementavam os conteúdos.

Além disso, as atividades semanais eram compostas por uma WebQuest e um Fórum de Discussão. Elas eram liberadas nas segundas-feiras logo após a aula presencial e com o fechamento aos sábados. Dessa forma, além dos alunos estarem aprendendo sozinhos no tempo em que eles determinavam, as atividades permitiam uma ampla discussão entre todos os envolvidos fora da sala de aula. Foi perceptível a participação e interação dos alunos nas pesquisas e discussões nos fóruns. O grupo criado no Whatsapp foi utilizado frequentemente entre os alunos para tirar dúvidas rápidas sobre os conteúdos.

Como atividades à distância, foram realizados os seguintes Webquests: 1 - Cada aluno teria que escolher uma linguagem de programação e fazer um breve resumo sobre a mesma; 2 - Explicar a diferença entre Hardware e Software; 3 - Responder exercícios de raciocínio lógico; 4 - Diferenciar cada símbolo referente aos operadores lógicos. Os Fóruns de Discussão abordaram os seguintes temas: 1- Expresse suas opiniões sobre a importância do ensino de programação na educação básica; 2 - Pesquise o que é lógica de Programação e apresente exemplos práticos de algoritmos do dia-a-dia; 3 - Comente sobre a importância da evolução dos computadores; 4 - Assistam o vídeo (Lançamento de Cabos Submarinos) e comentem suas opiniões em relação à evolução tecnológica;

Como evidência, a Figura 3 apresenta a resposta de um dos alunos em relação à WebQuest da primeira semana à distância, onde individualmente teriam que pesquisar e relatar pontos importantes sobre alguma linguagem de programação que tivesse despertado maior interesse e curiosidade. Para executar as atividades, os mesmos recebiam orientações sobre como efetuar suas pesquisas e a importância de deixar sobre fácil acesso às fontes utilizadas.

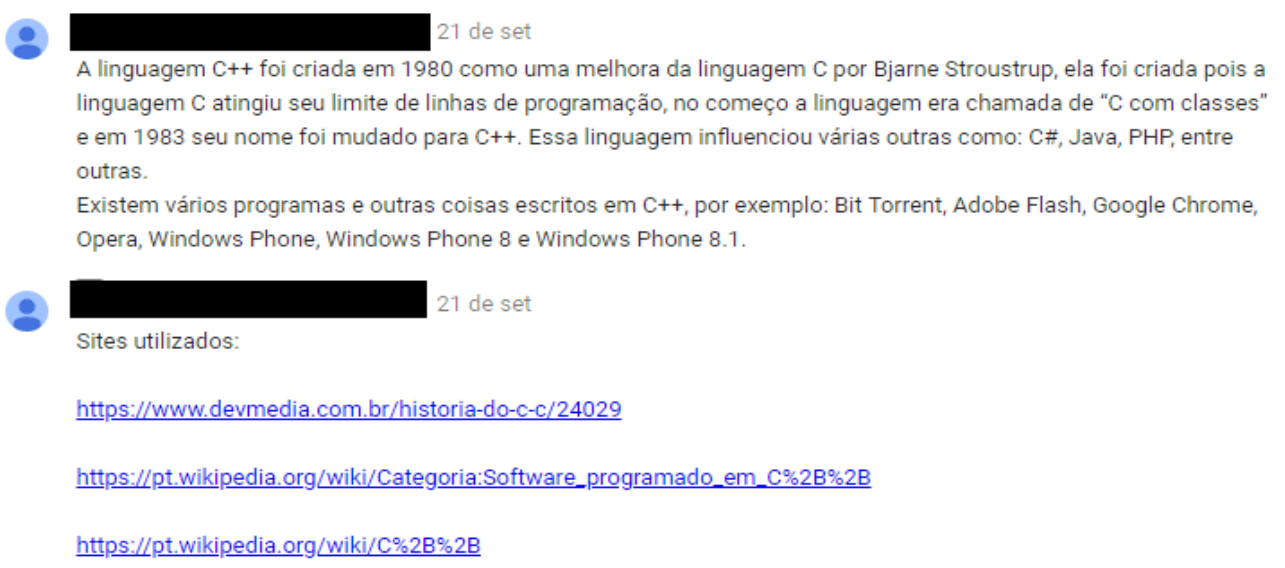

Figura 3. Respostas dos alunos no Google Classroom.

\section{Considerações finais}

Diante do contexto tecnológico e de aprendizagem atual, introduzir conceitos de Computação na educação básica, enquanto ciência, contribui para o desenvolvimento de habilidades essenciais aos alunos do século XXI. Além disso, perspectivas de trabalhar com a modalidade semipresencial têm se tornado cada vez mais possível 
tecnologicamente e estimulado a autonomia dos alunos para organizar seus próprios horários e realizar suas atividades onde quiserem por diversos meios e dispositivos, tais como computador, smartphone e tablet.

Nesse aspecto, o presente artigo relatou uma experiência de ensino e aprendizagem dos conceitos básicos de programação para alunos do $7^{\circ}$. ano do Ensino Fundamental por meio de um curso semipresencial e com uma abordagem lúdica. Com isso, foi possível observar o potencial das ferramentas lúdicas para a aprendizagem dos conteúdos propostos. Além de evidenciar a eficácia de utilização do Google Classroom e do Whatsapp para fins educativos. Tal conclusão encontra-se fundamentada na motivação e facilidade de associação dos conceitos ensinados, demonstrados pelas falas dos alunos no decorrer do curso, conforme demonstrado na Figura 2.

Aponta-se como principal limitação deste trabalho a curta duração do curso. Apesar dos resultados positivos, acredita-se que sua aplicação em um período mais longo possibilitará uma análise mais completa, principalmente acerca das aulas à distância. Ressalta-se que esse período foi definido pelos professores da disciplina de Estágio Supervisionado do curso de Licenciatura em Computação. Na perspectiva dos Licenciandos em Computação, destaca-se o quão difícil é manter os alunos engajados durante as aulas presenciais e, principalmente à distância. As atividades e dinâmicas lúdicas agiram como um elemento que contribuiu para motivar os participantes ao longo do percurso. Além disso, enfatiza-se a inexperiência dos licenciados nessa modalidade de ensino.

Considera-se que essa iniciativa teve contribuições tanto para os alunos do curso como também para os Licenciandos em Computação. O contato com a sala de aula, em especial com a modalidade de educação semipresencial, proporcionou aos integrantes as práticas docentes ainda no âmbito da graduação. Por fim, sugere-se como trabalhos futuros: a realização de um curso mais extenso e com a ampliação do público-alvo; a inclusão de plataformas de desenvolvimento de jogos educativos na ementa do curso, como por exemplo, Game Maker"; e possibilitar aos alunos a aplicação dos conceitos de Computação na resolução de problemas das disciplinas do currículo escolar, tais como, matemática, geografia, física, etc.

\section{Referências}

BAIRRAL, M. A. (2007) Discurso, Interação e Aprendizagem matemática em ambientes virtuais a distância. Seropédica: Edur.

Bell, T.; Witten, I. e Fellows, M. (2011). "Computer Science Unplugged - Ensinando Ciência da Computação sem o uso do Computador", Tradução de Luciano Porto Barreto, 2011.

Belloni, M. (1999) Educação a distância. Coleção Educação Contemporânea, Ed Autores Associados, 115 pág.

Bertagnolli, S. C., et al. (2008) Potencialidades e Desafios da Modalidade Semipresencial. Novas Tecnologias na Educação, v. 6, n.1, pág. 1-10.

BETTEGA, Maria H. S. (2010) Educação continuada na era digital. 2 ed São Paulo: Cortez.

"Ver em https://www.yoyogames.com/studio 
DODGE, B. (2006) WebQuests: past, present and future. In A. A. Carvalho (org.), Atas do Encontro sobre Web Quest. Braga: CIEd.

FERREIRA, M. A. et al (2015). Computação para Ensino Médio na Modalidade Semipresencial: Uma Experiência da Disciplina de Estágio Supervisionado. XXIII Workshop de Educação em Computação (WEI).

JÚNIOR, J. et al (2005). Ensino de Algoritmos e Programação: Uma Experiência no Nível Médio. XIII Workshop de Educação em Computação (WEI).

KAFAI, Y. B. e BURKE, Q. (2013). Computer Programming Goes Back to School. In: Education Week, set.

LEVY, P. (2008) Cibercultura. $7^{\text {a }}$ ed. São Paulo: Editora 34.

MENEZES, I. M., GITAHY, R. R. C. (2010). “A utilização do computador no processo de ensino/aprendizagem por professores do $6^{\circ}$ ano do ensino fundamental do município de Paranaíba - MS”. Portal de Periódicos da UEM.

MORAN, J. M. (2005) Tendências da educação online no Brasil. In RICARDO, Eleonora Jorge (Org.). Educação Corporativa e Educação a Distância. Rio de Janeiro: Editora Qualitymark.

MOREIRA, A. F. B et al (2007). Contemporaneidade, Educação e Tecnologia. Disponível em: <http://www.scielo.br/pdf/es/v28n100/a1928100.pdf> Acessado em Novembro 2018.

Neto, S., Santos, H., Souza, A., Santos, W . (2013) Jogos Educacionais como Ferramenta de Auxílio em Sala de Aula. In: Anais XIX Workshop de Informática na Escola (WIE 2013), Campinas - SP, pág. 130-139.

OLIVEIRA, M. L. S. et al. (2014) Ensino de lógica de programação no ensino fundamental utilizando o Scratch: um relato de experiência. XXXIV CSBC.

PÍCCOLO, L. et al (2010) Ambiente Interativo e Adaptável para ensino de Programação.

PONTE, J.; OLIVEIRA, H. e VARANDAS, M. (2003) O contributo das tecnologias de informação e comunicação para o desenvolvimento do conhecimento e da identidade profissional. In: FIORENTINI, D. (Org.) Formação de Professores de Matemática: Explorando novos caminhos com outros olhares. Campinas: Mercado de Letras.

RAMAL, A. C. (2002). Educação na cibercultura. Porto Alegre: Artmed.

SCAICO, P. D. et al. (2013) Ensino de Programação no Ensino Médio: Uma Abordagem Orientada ao Design com a linguagem Scratch. RBIE, v. 21, n. 02, p. 92.

SCHOEFFEL, P. et al. (2015) Uma Experiência no Ensino de Pensamento Computacional e Fomento à Participação na Olimpíada Brasileira de Informática com Alunos do Ensino Fundamental. Anais dos Workshops do IV CBIE.

SILVA, M. (2003) Educação online. São Paulo: Loyola.

UPE (2015) "Manual de Estágio Supervisionado das Licenciaturas da UPE - Campus Garanhuns". Disponível em: <http://www.upe.br/garanhuns/wpcontent/uploads/2014/10/MANUAL-EST\%C3\%81GIO-LICENCIATURAS-

GARANHUNS-2015.pdf > . Acesso em: 20 de março de 2019.

Voigt, E (2007) A Ponte Sobre o Abismo: Educação Semipresencial como Desafio dos Novos Tempos. Estudos Teológicos, vol 47, n 2. 